\title{
Biotechnology in forage crops - capturing our potential
}

\author{
G.T. BRYAN \\ AgResearch Grasslands, Private Bag 11008, Palmerston North \\ gregory.bryan@agresearch.co.nz
}

\begin{abstract}
Biotechnology will play an essential role in the economic future of New Zealand and in maintaining the global competitiveness of our forage-based primary production. The genomics era has added a new dimension to cultivar development, with marker-assisted selection allowing more precise genome modifications during plant breeding, and plant transformation providing more direct and novel routes to cultivar improvement. The biggest impact will be the ability of researchers to consider genetic pathways and networks rather than working on "single gene fixes". Integral to functional genomics are the rapidly developing fields of proteomics and metanomics - all these skills are needed to make a complete biotechnology package. Genetics and plant breeding have made a huge contribution toward forage crop performance in pasture-based systems, and biotechnology will provide future innovations and opportunities. Several research groups worldwide are developing comprehensive genetic maps of white clover and perennial ryegrass and are linking these to functional analysis of sequence databases to identify agronomically important genes. For this approach to capture its full value, researchers will need to fully integrate functional genomics with genetics, biochemistry, plant biology, agronomy and farm system management. Strong mapping, gene discovery, functional genomics and transformation capabilities will allow high-throughput analysis of gene function and application in new cultivars, using marker-assisted breeding or in transgenic lines. These tools provide an exciting opportunity to tackle some of the challenges faced in optimising pasture-based farming systems.
\end{abstract}

Keywords: biotechnology, functional genomics, gene discovery, marker-assisted selection, perennial ryegrass, plant breeding, transgenic, white clover

(A glossary of terms is on page 239.)

\section{Introduction}

The use of biotechnology in commercial crop and forage cultivar development is a dominant focus of international biotechnology companies and research groups. The genomics era has realised the potential for forage cultivar development on a scale not previously available to traditional plant breeders. The New Zealand Royal Commission on Genetic Modification has recognised the importance of biotechnology in New Zealand's future. The challenge researchers face is to take full advantage of this technology in a responsible and sustainable way. Plant breeders have a new technology available for development of élite cultivars that is most effective when there is a seamless integration of plant genomics with biology, genetics, biochemistry, mapping, breeding and agronomy.

Transgenic crops have been on the market in the USA for over 10 years. Until recently, most of the transgenic traits have been input traits (a trait that directly benefits the farmer and is not passed on to the consumer) such as pest and disease resistance or herbicide tolerance. This is because the initial input traits were obvious and led to easy ways to develop profitable cultivars. However, biotechnology has also aided plant breeders in developing many crops that contain output traits (the trait directly benefits the consumer) such as wheat with novel starch properties for food products. The second generation of transgenic crops will contain many more output traits (e.g., golden rice or soy oil with increased shelf life).

Input traits that are important in New Zealand forage crops are involved with increasing plant yield and persistence or increasing milk and meat production in animals. However, there are also some challenging targets that could directly benefit the consumer including forage that leads to healthier milk and meat. The main New Zealand research funding agency, the Foundation for Research, Science and Technology (FRST), has indicated that the future direction of publicly funded research in plant gene technologies in New Zealand will move away from more traditional targets of production and efficiency toward areas such as human health and well-being, products for the biotechnology industry and advanced materials. This 
provides an exciting and challenging opportunity to use novel solutions in the production of forage cultivars, and leverage knowledge from forage research to develop innovative new products. However, publicly funded New Zealand research organisations will not abandon the traditional areas of forage research. They will continue to work closely with industry partners (many of which fund research through farmer levies) and with seed companies on key areas that are important to New Zealand and international farming systems.

\section{Key targets in forage cultivar development}

Most forage researchers worldwide have focused traditionally on production and efficiency issues including increasing yield, persistence, resistance to pests and diseases, drought tolerance and energy availability. Importantly, AgResearch also has had a major research effort on endophyte symbiosis in perennial ryegrass and tall fescue that has led to products in the US and New Zealand (Easton et al. 2001). Several groups worldwide are working on increasing overall energy availability in forage. This is mainly because of the relative imbalance of protein over carbohydrate in forage that leads to excess ammonia in ruminants. The approach has been to modify fructan carbohydrate polymer biosynthesis in ryegrass and to transform fructan biosynthetic genes into white clover. There has been much effort on forage secondary metabolism, including condensed tannin and lignin biosynthesis. The beneficial effects of condensed tannins in forage for ruminants include improved productive performance and reduced dependence on anthelmintic drenches (Waghorn et al. 1998). The ability to control flowering in perennial ryegrass is also a target as this could reduce pollen allergens, contain transgenes and may maintain forage quality during the flowering season.

\section{Tools of biotechnology}

The use of biotechnology for development of improved or novel cultivars is usually centred on a strong genomics platform. It is absolutely essential for each agronomic target to focus initially on the biology of the system, so that the strategy and questions asked by structural and functional genomics techniques have a valid basis. As each project develops it is critical to come back to the biology and ask if the target or approach remain valid.

Gene Discovery: The most common gene discovery technique is the sequencing of random clones from cDNA libraries. This results in expressed sequence tags or ESTs (Adams et al. 1991). This technique allows rapid identification of candidate genes but with little genetic knowledge of the system. Identification is by comparison with gene sequences published in public or private databases. EST sequencing is biased toward highly expressed genes and can lead to redundancy in sequence databases. The efficiency of library sequencing can be greatly improved by library normalisation or subtraction techniques. When a candidate gene is identified within an EST database, further screening is usually required to obtain a fulllength cDNA. A genomic library screen is necessary to identify the regulatory sequences. There are also efficient systems for the enrichment of full-length cDNAs when producing a library. It is also possible to array random clones from libraries and obtain information on expression from different tissues or from different developmental stages or biotic and abiotic stress treatments. Only the subset of clones enriched for valuable candidate genes are taken forward for sequence analysis.

Several groups, including AgResearch, that undertake research on perennial ryegrass and white clover, have proprietary EST sequence databases containing tens of thousands of sequences. There is currently little perennial ryegrass (approximately 100 sequences) or white clover (approximately 40 sequences) sequence information in the public domain.

The ultimate method of gene discovery is full genome sequencing. Shotgun sequencing, where the plant chromosomes are sheared into small fragments, cloned and randomly sequenced is becoming increasingly popular. Sufficient sequencing capacity is required to identify the equivalent of up to eight genomes of sequence data. The sequence data are analysed by powerful sequence comparison programs, assembled into contiguous sequence alignments (contigs) and gaps filled to produce a consensus sequence, which is then scanned for gene candidates. Shotgun sequencing is very expensive and requires powerful sequencing bioinformatics platforms. Based on the technology we have today, it would be difficult to justify a similar approach in a forage species unless there was some form of international collaboration. ViaLactia Biosciences Ltd and Orion Genomics LLC are using a gene discovery procedure based on genomic sequencing called Gene Thresher ${ }^{\mathrm{TM}}$ to isolate perennial ryegrass genes. This technology will remove some of the bias for identification of highly expressed genes using EST sequencing.

Other effective methods of identifying valuable genes include gene-tagging techniques (Martienssen 1998; Weigel et al. 2000). Plants are followed up based on the mutant phenotype. The advantage of these systems over EST sequencing is that there is no bias 
from gene expression levels and a mutant line is on hand to aid identification of gene function.

Bioinformatics: Once a sufficiently large sequence database is available for the target species, it is then necessary to identify genes that confer valuable agronomic traits. Bioinformatics is an essential component of sequence database utilisation. Research groups within New Zealand either buy off-the-shelf bioinformatic software and optimise it for their applications, or they develop in-house packages. Using these packages, comparative searches with public domain or private sequence databases are performed. Clustering of EST sequence databases adds value by allowing identification of sequence contigs, identification of gene families, comparison clone representation in libraries (electronic northerns), and identification of potential single nucleotide polymorphisms that have utility in mapping.

Expression Analysis: Data on expression of candidate genes and those in the unknown category will also help assign function to genes in forages. There are several common techniques for simultaneous expression analysis of multiple genes. One of the highest-throughput techniques is microarray analysis that allows the assessment of expression of thousands of clones at once. Real-time polymerase chain reaction techniques are highly sensitive and allow analysis of different RNA splicing patterns. Systems exist for rapidly performing in situ hybridisation and the technique is more informative than hybridisation arrays. Proteomics involves the analysis of individual proteins using mass spectroscopy, following separation the total complement of proteins in a cell or tissue by high-resolution two-dimensional electrophoresis. Proteomics is more informative than the techniques described previously, as it also provides data on translation efficiency, protein stability and posttranslational modification.

Mapping: Integral to functional genomics is gene mapping, used both for mapping candidate genes on a genetic map and for map based cloning (see Barrett et al. 2001). Products of biotechnology can include conventionally bred forage varieties developed with the help of marker-assisted selection, and transgenic varieties. The key contribution of biotechnology to conventional breeding is the opportunity it provides to rapidly identify agronomically important genes and breed these into élite varieties using marker-assisted selection. The value of sequence databases for identification of molecular markers is immense. Sequence databases can be searched for microsatellite sequences, and sequences can also be clustered into contigs for identification of single nucleotide polymorphisms.

Plant transformation: Many of the techniques mentioned previously require efficient and reliable transformation systems. These are available for white clover and are in development for perennial ryegrass. Initially, analysis of gene function will be undertaken in model systems. Selection of transformed plant tissue is based on resistance to antibiotics or herbicides and efforts are underway to identify new selection systems for plant transformation that do not rely on antibiotic resistance but instead allow the plant tissue to utilise novel carbon sources. These so-called positive selection systems (Zhang et al. 2000) seem the likely choice for future transgenic products. In many commercial crops it takes $8-10$ years from having a gene in hand to go through the plant transformation, evaluation and seed production processes before commercial sales can begin. This is an expensive process so plant breeding options including marker-assisted selection normally need to be ruled out before using the plant transformation route.

Model system genomics: The ideal plant species for genomics studies should have an extensive genetic map, a small diploid genome, mutants in many or most genes, be self-fertile, have an efficient transformation system, have the entire genome sequenced and be of agronomic importance. Forage crops, including white clover and perennial ryegrass do not fit these criteria very well, but can benefit from analysis of several related species that are excellent model systems. Researchers generally use model plant systems that fit many of the criteria above to enable basic research to be carried out more rapidly than in many commercial crops. Arabidopsis thaliana has the entire genome sequenced and is the most widely studied model plant species. Rice may be an ideal model system for perennial ryegrass. Rice has a small diploid genome, an extensive genetic map and has a draft of the entire genome (Barry 2001). There are several useful model systems for white clover, including Arabidopsis and Medicago truncatula, a related legume.

Biochemistry: Extensive sequencing projects have identified large numbers of genes and the next step is to determine gene function, highlighting the importance of biochemistry. Apart from standard biochemical techniques there are also two important emerging fields, proteomics and metanomics. These two areas are currently in development at AgResearch to complement the plant genomics platform. Metanomics is the analysis 
of multiple metabolic profiles simultaneously using analytical mass spectroscopy techniques. These are often profiles of unknown compounds, the goal is to identify differences in metabolic profiles between different plant samples, and any differences are then further studied to determine the biochemical changes associated with these profiles. Metanomics will be useful for risk assessment of transgenic plant varieties and can be used to identify metabolic changes before and during experimental field testing.

Intellectual property: A common approach for identifying agronomically valuable genes is to use information from characterised genes within the public domain. This is becoming more efficient now that there are commercially available databases and several sequence databases in GenBank. Annotation of sequence databases is an essential step to add full value to a sequence database, and it allows the initiation of robust intellectual property (IP) portfolio development. Filing provisional patents on key gene sequences is a rapid way of obtaining IP protection however, additional information on gene function is required to obtain a robust IP position. One's IP position can also be affected by the IP of parties that have originally identified the genes used to search a database. Identification of novel gene function or utility will provide the strongest IP position. Therefore, the ESTs in a sequence database that have little or no similarity to known genes may well be the most valuable.

\section{The present}

AgResearch, in collaboration with Agriculture Victoria, has developed proprietary perennial ryegrass and white clover EST databases, and have moved past the discovery phase into a functional genomics approach toward assessing gene value and function. The combination of skills within AgResearch and Agriculture Victoria including sequencing, functional genomics, mapping, breeding, agronomy, germplasm collections, ruminant nutrition research, and links to industry make a powerful combination that will deliver biotechnology solutions to the Australasian and international farming sectors. The goal of the collaboration is to develop technology that can then be licensed to industrial partners and seed companies to give Australasia a competitive advantage over international markets.

ViaLactia Biosciences Ltd are currently building their plant gene technologies platform and have recently established an alliance with Orion Genomics LLC. Likewise, Wrightsons and Genesis have announced a research agreement in perennial ryegrass biotechnology and also have a proprietary sequence database. These companies already interact on various areas of forage breeding and biotechnology and are building stronger links to other Crown Research Institutes, and to various New Zealand Universities. The latter are likely to increase the availability of graduate students to all groups and importantly to provide students with further experience and training in the plant biotechnology area. This is an important successional planning step to provide highly trained graduates for New Zealand.

\section{Five years from now}

Owing to New Zealand's size and relatively small science budget (in comparison to the large international biotechnology companies) it is likely that the different groups working on forages will have to build closer ties to maximise their competitive advantage. Several groups that have sequencing projects on white clover and perennial ryegrass including AgResearch, ViaLactia Biosciences and Wrightsons will have many competitive and complementary research targets. All groups will wish to maximise advantage and minimise research costs, but collaboration will be on a project-by-project basis as required by research agreements with third parties. These alliances will place New Zealand and Australasia in a tremendous competitive advantage.

Products that will greatly benefit the New Zealand farmer will arise initially from marker-assisted breeding strategies that are enhanced by biotechnological approaches toward forage research. Plant transformation pipelines will be optimised and it is likely that positive selection systems will replace antibiotic selection. AgResearch and associated research groups will be in a position to capitalise on the major advances in the biotechnology area that are certain to eventuate.

The New Zealand farming sector will be an important focus but products will also be targeted at the global market to capture the opportunities and their high potential value. There will be an emphasis on products that benefit consumer health or have utility for other biotechnology or pharmaceutical industries.

\section{REFERENCES}

Adams, M.D.; Kelley, J.M.; Gocayne, J.D.; Dubnick, M.; Polymeropoulos, M.H.; Xiao, H., Merril, C.R.; Wu, A., Olde, B.; Moreno, R.F. et al. 1991. Complementary DNA sequencing: expressed sequence tags and human genome project. Science 252(5013): $1651-1656$. 
Barrett, B.; Griffiths, A.; Mercer, C.F.; Ellison, M.; Faville, M.; Easton, H.S.; Woodfield, D.R. 2001. Marker-assisted selection to accelerate forage improvement. Proceedings of the New Zealand Grassland Association 60: 241-245.

Barry, G.F. 2001. The use of the Monsanto draft rice genome sequence in research. Plant Physiology 125: 1164-1165.

Easton, H.S.; Christensen, M.J.; Eerens, J.P.J.; Fletcher, L.R.; Hume, D.E.; Keogh, R.G.; Lane, G.A.; Latch, G.C.M.; Pennell, C.G.L.; Popay, A.J.; Rolston, M.P.; Sutherland, B.L.; Tapper, B.A. 2001. Ryegrass endophyte: a New Zealand Grassland success story. Proceedings of the New Zealand Grassland Association 60: 37-46.

Martienssen, R.A. 1998. Functional genomics: probing plant gene function and expression with transposons. Proceedings of the National Academy of
Sciences of the United States of America 95: 20212026.

Waghorn, G.C.; Douglas, G.B.; Neizen, J.H.; McNabb, W.C.; Foote, A.G. 1998. Forages with condensed tannins - their management and nutritive value for ruminants. Proceedings of the New Zealand Grassland Association 60: 89-98.

Weigel, D.; Hoon Ahn, J.; Blazquez, M.A.; Borevitz, J.O.; Christensen, S.K.; Fankhauser, C.; Ferrandiz, C.; Kardailsky, I.; Malancharuvil, E.J.; Neff, M.M.; Thuy Nguyen, J.; Sato, S.; Wang, Z-Y.; Xia, Y.; Dixon, R.A.; Harrison, M.J.; Lamb, C.J.; Yanofsky, M.F.; Chory, J. 2000. Activation tagging in Arabidopsis. Plant Physiology 122: 1003-1013.

Zhang, P.; Potrykus, I.; Puonti-Kaerlas, J. 2000. Efficient production of transgenic cassava using negative and positive selection. Transgenic Research 9: 405-415.

\begin{tabular}{|c|c|}
\hline \multicolumn{2}{|l|}{ Glossary of terms } \\
\hline bioinformatics & $\begin{array}{l}\text { The study of DNA and protein sequences using a vast set of computer programmes that help researchers } \\
\text { predict gene function and annotate a sequence database. }\end{array}$ \\
\hline biotechnology & The exploitation of biological processes for industrial and other processes, especially the genetic manipulation. \\
\hline cDNA & $\begin{array}{l}\text { Complementary DNA. A DNA copy of messenger RNA, the transcribed parts of genes. Messenger RNA is the } \\
\text { template for translation of a gene into protein. }\end{array}$ \\
\hline cDNA & A large collection (library) of cDNAs that are cloned and replicated in bacteria. \\
\hline clone & $\begin{array}{l}\text { Isolated DNA that is inserted into a bacterial vector and replicated for analysis and manipulation. Not to be } \\
\text { confused with a cloned organism - an identical genetic copy of the parent (e.g., Dolly the sheep). }\end{array}$ \\
\hline electro & The separation of nucleic acids or proteins based on their molecular weight under an electric current. \\
\hline endoph & A fungal symbiont living in plant tissue. \\
\hline ESTs & $\begin{array}{l}\text { Expressed sequence tags, cDNAs that are cloned, selected at random and partially sequenced. This sequence } \\
\text { tag (usually } 500 \text { to } 700 \text { nucleotides) is subjected to bioinformatic analysis. }\end{array}$ \\
\hline fructan & $\begin{array}{l}\text { A glucose sugar molecule linked to a polymer of fructose molecules. Fructans are found naturally in perennial } \\
\text { ryegrass and other plant species. }\end{array}$ \\
\hline functio & The functional analysis of genes using multiple techniques. \\
\hline gene & $\begin{array}{l}\text { All cells contain a complete set of genes in their chromosomes, but at any one time only a fraction of these are } \\
\text { actively producing RNA (expressed) and proteins. Genes can be expressed at different levels. }\end{array}$ \\
\hline genome & The entire complement of DNA in a cell. \\
\hline genomics & The study of the genome by sequencing. \\
\hline genomic lib & A large collection (library) of genomic fragments that are cloned and replicated in bacteria. \\
\hline microarray & $\begin{array}{l}\text { A high-density array (often on a glass slide) of thousands of clones (usually ESTs) that are hybridised to } \\
\text { fluorescent cDNA from various plant tissues. }\end{array}$ \\
\hline microsatellite & $\begin{array}{l}\text { Simple sequence repeat. A region in a chromosome that has a small number of di-, tri-, tetra- or penta- } \\
\text { nucleotide repeats (e.g., ATTATTATTATTATTATT). The sequence flanking the repeats is normally conserved } \\
\text { however, the number of repeats can vary within populations, and the difference in size is used as a diagnostic } \\
\text { marker (see Barrett et al. 2001). }\end{array}$ \\
\hline transformation & $\begin{array}{l}\text { The introduction and stable inheritance of foreign genes into an organism. With plants this is normally done } \\
\text { using Agrobacterium or the gene gun. }\end{array}$ \\
\hline transgenic plant & A plant that has been transformed, i.e., a genetically modified organism. \\
\hline
\end{tabular}

